\title{
Riscos das mídias e tecnologias na capacitação para cuidadores de idosos: estudo de caso
}

\section{Risks of media and technologies in training for caregivers of elderly: a case study}

\author{
Vilmar da Conceição Oliveira Filho' • Selma Petra Chaves Sá $\bullet$ Rafael da Silva Soares ${ }^{3}$ \\ Cristian Antonio Brezolin $\bullet$ Ana Lucia Leitão Caldas ${ }^{5}$ Thaís de Rezende Bessa Guerra ${ }^{6}$
}

\begin{abstract}
RESUMO
Objetivou-se orientar cuidadores de idosos em um curso de capacitação no Centro de Atenção à Saúde do Idoso e seu Cuidadores, Universidade Federal Fluminense, sobre as principais carências e necessidades nutricionais requeridas pelos próprios e pelos idosos, alertando ainda sobre os riscos das tecnologias. Trata-se de um estudo de caso do estágio de docência, sobre a capacitação de cuidadores, enquanto mestrando acadêmico do Programa de Ciências do Cuidado em Saúde.A compreensão e visualização acerca da organização e planejamento das demandas cotidianas requisitadas de um profissional acadêmico em suas palestras/cursos/oficinas. Conclui-se que há necessidade de uma capacitação dos pós-graduandos nos métodos de transmissão dos conhecimentos acadêmicos, como por exemplo, a linguagem utilizada para os cuidadores, objetivando assim a compreensão de toda a turma e alertando sobre os riscos das influências tecnológicas na baixa qualidade alimentar ingerida.
\end{abstract}

Palavras-chave: Educação; Ensino em Enfermagem; Nutrição.

\section{ABSTRACT}

The aim of this study was to orient elderly caregivers in a training course at the Center for Health Care of the Elderly and its Caregivers, Federal Fluminense University, about the main needs and nutritional needs required by the elderly and the elderly, also warning about the risks of the technologies. This is a case study of the teaching stage, about the qualification of caregivers, as an academic master of the Health Care Sciences Program. Understanding and visualization about the organization and planning of the daily demands of an academic professional in their lectures/courses/workshops. It is concluded that there is a need for the training of postgraduates in the methods of transmission of academic knowledge, such as the language used for caregivers, aiming at understanding the whole class and warning about the risks of technological influences in the low food quality.

Keywords: Education; Teaching, Nursing; Nutrition.

\footnotetext{
'Nutricionista. Mestre em Ciências do Cuidado em Saúde da Universidade Federal Fluminense - UFF. Pós-graduado em Ciências da Performance Humana - UFRJ. Niterói, RJ - Brasil. Endereço:Avenida Jansen de Mello 174, Centro, Niterói, RJ. Campus Mequinho. CEP 24030-22I. E-mail: vilmarcof@hotmail.com ${ }^{2}$ Enfermeira. Pós-doutorado em Enfermagem e Professora Titular da Escola de Enfermagem Aurora de Afonso Costa da Universidade Federal Fluminense - UFF. Niterói, RJ, Brasil

${ }^{3}$ Enfermeiro. Mestre em Ciências do Cuidado em Saúde da Universidade Federal Fluminense (UFF). Niterói, RJ, Brasil.

${ }^{4}$ Enfermeiro. Mestrando em Ciências do Cuidado em Saúde da Universidade Federal Fluminense (UFF)

${ }^{5}$ Farmacêutica. Mestre em Ciência do Cuidado em Saúde da Universidade Federal Fluminense (UFF). Niterói, RJ, Brasil

${ }^{6}$ Nutricionista. Mestre em Ciências Médicas e Doutora em Ciências Cardiovasculares da Universidade Federal Fluminense (UFF). Niterói, RJ, Brasil
} 


\section{INTRODUÇÃO}

Diante dos crescentes avanços tecnológicos, o profissional acadêmico necessita de técnicas e métodos eficazes em sua prática diária. Os métodos tecnológicos, como as imagens, estimulam e devem ser valorizados de forma a contemplar as necessidades específicas de cada turma, almejando transmitir o conhecimento de maneira clara e objetiva, possibilitando o entendimento e a compreensão dos alunos. Deve-se ainda ressaltar as trocas de saberes pautada na dialogicidade, pois ninguém é detentor de todo o conhecimento, a interação se faz necessária na construção do saber desejado(').

Essa capacidade de diálogo e troca de experiências promovem o crescimento do profissional e acadêmico de saúde em formação, no presente caso, o nutricionista e, principalmente, desmistifica do mesmo a visão mecanicista e verticalizada, proporcionando a ampliação da visão do ser humano como um todo, e não apenas como um indivíduo carente de conhecimento ou carente de saúde ${ }^{(2)}$.

Dado o exposto, em 1999, a Coordenação de Aperfeiçoamento de Pessoal de Nível Superior (CAPES) implementou o estágio à docência nos cursos de pós-graduação stricto sensu, mestrado e doutorado, objetivando a formação de professores com plena capacidade atentiva às necessidades dos indivíduos que estão em formação $\mathrm{e}$ com intuito de promover os avanços científicos em todas áreas, no presente artigo, na Área da Saúde. Entretanto, vale lembrar que tal atividade é sempre realizada sob a supervisão do seu professor orientador, conforme regulamentação da Portaria n..$^{\circ} 76$, de 14 de abril de 2010, do Ministério da Educação(3).

Nesse viés, os programas de estágio à docência desenvolvidos pelo Programa Acadêmico de Ciências do Cuidado em Saúde, permitem aos mestrandos/doutorandos, subsídios para uma formação ampla e com oportunidades de questionamento a todo o momento.

$\mathrm{O}$ que inquietou e motivou a escrita foram os questionamentos incessantes dos cuidadores sobre alimentação dos próprios cuidadores e, em segundo plano, a dos idosos, o que caracteriza o desejo de conhecimento alimentar do cuidador sobre a qualidade dos alimentos difundidos no mercado brasileiro.

O presente artigo se mostra relevante para as futuras pesquisas, pois a necessidade de instruir os cuidadores aos cuidados alimentares com a utilização de métodos expositivos e esclarecedores são formas de mostrar de fato os teores de açúcar e sal nos alimentos de consumos fáceis devido às rotinas diárias. Portanto, se fez a seguinte pergunta: Apenas o rótulo nutricional se mostra esclarecedor para a saúde dos seres humanos, especificamente dos cuidadores?

\section{MÉTODO}

Estudo de caso com caráter descritivo, oriundo de uma pesquisa quantitativa longitudinal com o título: "In- tervenção nutricional e implicações na qualidade de vida dos cuidadores de idosos", do Mestrado Acadêmico em Ciências do Cuidado em Saúde da Universidade federal Fluminense (UFF). $\mathrm{Na}$ atividade realizada, em um primeiro momento, foi realizada a apresentação dos integrantes com a exposição dos teores de carboidratos e sódios nos alimentos, a fim de socializar os envolvidos e quebrar o paradigma opressor do professor/profissionais/graduandos como detentor de todo o saber ${ }^{(1)}$. $O$ estudo teve como critérios de inclusão: cuidadores já cadastrados no Centro de Atenção à Saúde do Idoso e seus Cuidadores (CASIC/ UFF), com a idade dos 20 a 59 anos; e como critérios de exclusão: grávidas, portadores de marca-passo e quem já estivesse recebendo acompanhamento nutricional. Foi realizado no período de abril de 2018 .

O estudo obedeceu a Resolução $n^{\circ} .466 / 12$ do Conselho Nacional de Saúde (CNS), junto ao CAAE, n. ${ }^{\circ}$ 766036 |7.9.0000.5243 e do parecer do Comitê de Ética em Pesquisa da Faculdade de Medicina da Universidade Federal Fluminense (CEP/FMUFF), n. ${ }^{\circ}$ 2.386.997.

\section{ESTUDO DE CASO}

A oficina era composta por 28 alunos do curso de capacitação de cuidadores de idosos, predominantemente composta por mulheres e na faixa etária adulta. A orientação foi ministrada em uma sala do CASIC, localizado em Niterói - Rio de Janeiro - Brasil.

Primeiramente, como forma de planejamento foi elaborado um plano de aula com tópicos indispensáveis na orientação e, posteriormente à reflexão da elegibilidade dos mesmos, realizou-se uma aula com animações utilizando o retroprojetor, objetivando a todo o momento conquistar e manter a atenção da turma de cuidadores.

Os temas utilizados foram: macronutrientes (carboidrato, proteína e lipídeo) através da recorrente e fundamental pirâmide alimentar, micronutrientes (vitaminas e minerais) e um tópico especial sobre hidratação, visto que o idoso devido ao envelhecimento acaba por não consumir água nos níveis adequados à manutenção fisiológica. Devido a este preocupante problema, o cuidador deve estar atento e estimular o consumo de água, zelando pela saúde do ser que está necessitando do ato do cuidado(4).

Posteriormente à parte teórica, foi apresentado ao grupo saquinhos plásticos contendo a quantidade/teor de sódio e carboidrato de diversos tipos de alimentos utilizados por grande parte da população, objetivando a visualização e maior conscientização do grupo sobre a qualidade de sua ingestão nutricional e a do idoso que está recebendo o cuidado, almejando estimular uma alimentação saudável. É valido ressaltar que a escolha dessa metodologia foi utilizada em uma capacitação de cuidadores como forma de facilitar a assimilação do conteúdo. 
A prática da capacitação apresentou-se ao como uma forma de articular todo o conteúdo teórico na realidade da prática. Possibilitou a articulação do planejamento, organização e métodos utilizados para facilitar a compreensão de toda a turma de cuidadores.

A aula foi realizada de maneira dinâmica, permitindo o questionamento a todo instante por parte dos cuidadores e de forma a evitar as dúvidas que poderiam surgir ao longo do tempo preconizado, visto que muitos dos presentes possuíam dúvidas sobre métodos de alimentação saudável para si mesmo e para os idosos, o que atualmente possui alta repercussão nos meios de comunicação.

Devido a isso, se observou também que grande parte dos cuidadores possuía informações sobre alimentação provenientes da internet e propagandas, tais informações em quase totalidade eram errôneas, o que deve ser combatido pelo profissional nutricionista, objetivando a disseminação da alimentação adequada ou reeducação alimentar personalizada.

O retroprojetor foi utilizado como meio de facilitar a exibição de imagens dos alimentos em seus respectivos grupos, no caso os macronutrientes, como exemplo: as carnes, que pertencem aos grupos dos proteicos, as massas e pães, pertencentes ao grupo dos carboidratos e as gorduras em geral como o óleo, constituinte do grupo dos lipídeos.

A metodologia expositiva da utilização de embalagens plásticas contendo a quantidade de sódio e carboidrato em cada alimento se mostrou como um método eficaz e facilitador de entendimento e compreensão da turma acerca da qualidade nutricional contida nos alimentos que são comumente difundidos e consumidos por grande parte da população. Tal método induziu aos alunos uma reflexão crítica acerca da ingestão nutricional dos mesmos e, principalmente, dos idosos que necessitam do cuidado, promovendo a educação em saúde através das diversas formas de tecnologias educacionais, pois as propagandas/mídias ainda informam pouco sobre os ingredientes que compõem o alimento, se tornando assim, em muitos dos casos, perigosas ${ }^{(5)}$.

\section{DISCUSSÃO}

O questionamento recorrente dos cuidadores acerca da qualidade dos alimentos ingeridos e os teores de açúcar e sódio, contido nos mesmos, foi recorrente, apontando a necessidade de estimular pesquisas, objetivando promover o entendimento dos cuidadores acerca da qualidade alimentar que os mesmos ingerem, além de sensibilizá-los para as influências que as tecnologias acabam por exercer no padrão de consumo alimentar cotidiano ${ }^{(6,7)}$.

É válido ressaltar que no mundo globalizado atual as tecnologias têm capacidade de disseminação de informações em segundos, afirmando os riscos que as mesmas possuem de influência nos hábitos alimentares de uma população(8).

A magnitude da influência de uma propaganda televisiva, por exemplo, na alimentação de uma pessoa é enorme, visto que as rotinas de trabalho se colocam cada vez mais intensas e agilizar as preparações alimentares tem se tornando quase que uma imposição das empresas empregadoras e das grandes indústrias alimentícias( ${ }^{(8)}$.

Nos dias atuais, essa rotina acaba por induzir ao consumo de alimentos, micro e ultraprocessados, os chamados de rápido preparo, o que é um risco para a saúde da população em geral, no presente artigo, dos cuidadores de idosos e dos que estão recebendo os cuidados. Esses alimentos têm baixo valor biológico/nutricional e são diretamente relacionados com os riscos de desenvolvimento das doenças crônicas não transmissíveis, entre essas doenças se destacam a diabetes mellitus e a hipertensão arterial(8,9,10).

A partir desse contexto, se afirma necessária a fiscalização minuciosa das mídias sociais e sua capacidade de influência nos padrões alimentares da população de cuidadores de idosos, possibilitando minimizar os possíveis riscos na qualidade do trabalho desenvolvido e na própria saúde do indivíduo, requerendo atenção redobrada nos aspectos que causam dificuldades no cotidiano do cuidador, sendo um destes a questão alimentar, necessitando dos profissionais da nutrição na elaboração e vigilância dos conteúdos tecnológicos elaborados ${ }^{(8,11,12)}$.

\section{CONCLUSÃO}

Posteriormente a experiência vivida, pode-se concluir que independente da área da saúde ou de qualquer outro campo da ciência, o ser humano se interessa a cada dia mais pela qualidade dos alimentos que ingere. $E$ essa busca pelo esclarecimento das possíveis dúvidas oriundas das influências tecnológicas devem ser solucionadas pelos profissionais da nutrição.

Objetivando evitar os possíveis erros, indica-se a implementação de ao menos um módulo ou carga horária de orientações nutricionais no ensino aos cuidadores de idosos, tornando o cuidado holístico e almejando evitar erros na alimentação do cuidador em questão, e que possa se refletir na qualidade da alimentação do idoso. Afirmando assim, a necessidade de atenção especial na saúde do próprio cuidador em sua rotina exaustiva.

Portanto, conclui-se que a orientação nutricional no ensino em uma capacitação de cuidadores de idosos se faz necessária como forma de alcançar o cuidado holístico e reduzir os riscos à saúde tanto do cuidador como também do idoso submetido aos seus cuidados. $O$ estudo teve a limitação de ter público alvo apenas os cuidadores idosos na faixa etária adulta e contribui para futuras pesquisas acadêmicas e clínicas relacionadas aos cuidadores de idosos, que acaba por ser um membro esquecido da sociedade. 


\section{REFERÊNCIAS}

I Freire P. Pedagogia do oprimido. 5. ed. São Paulo: Paz e Terra; 2011.

2 Santos LAS. O fazer educação alimentar e nutricional: algumas contribuições para reflexão. Cienc Saúde Cole 2012; 17(2): 453-62.

3 Ministério da Educação (Brasil). Portaria CAPES n 76, 14 de abril de 2010. Aprova o Regulamento do Programa de Demanda Social.

4 Genaro S, Gomes FHM, lenaga KK. Análise do consumo de água em uma população de idosos. Colloquium Vitae 2016; $7(2): 1-12$.

5 Áfio ACE, Balbino AC, Alves MDS, Carvalho LV, Santos MCL, Oliveira NR. Análise do conceito de tecnologia educacional em enfermagem aplicada ao paciente. Rev Rene 20I4; I5(I).

6 Pope L, Latimer L, Wansink B. Viewers vs. Doers. The relationship between watching food television and BMI. Appetite 2015; 90: I3I-5.

7 David IA, Krutman L, Andrade JR, Araújo RL, Braga F, Gomes FS et al. Pistas implícitas e obesidade: estratégias de pro- teção contra o marketing de alimentos. Demetra Aliment Nutr Saúde 20 I 6; I I (2): 383-98.

8 Sharma P, Rani MU. Effect of digital nutrition education intervention on the nutritional knowledge levels of information technology professionals. Ecol Food Nutr 2016; 55(5): 442-55.

9 Louzada MLC, Martins APB, Canella DS, Baraldi LG, Levy RB, Claro RM et al. Impacto de alimentos ultraprocessados sobre o teor de micronutrientes da dieta no Brasil. Rev Saúde Publ 2015; 49:I-12.

10 Assumpção D, Domene SMA, Fisberg RM, Barros MBA. Qualidade da dieta e fatores associados entre idosos: estudo de base populacional em Campinas, São Paulo, Brasil. Cad Saúde Publ 2014; 30(8): 1680-94.

I I Pereira LSM, Soares SM. Fatores que influenciam a qualidade de vida do cuidador familiar do idoso com demência. Cienc Saúde Cole 20I5; 20(I2): 3839-5I.

12 Cunha CV, Berardinelli LMM, Santo FHE. A percepção do cuidador de idosos no contexto de sua prática cotidiana em uma instituição de longa permanência. Rev Enferm Atual. 2018; 85:21-8. 